\title{
Analysis on the Cost Control of Manufacturing Enterprise
}

\author{
Liu Hongmei \\ Shandong Huayu University, Shandong, China, 253034
}

\author{
Keywords: Manufacturing Enterprise; Cost Control; Analysis
}

Abstract: With the entrance of the new socialist era of our country, the manufacturing industry of our country has been facing with the challenge of transformation and upgrading in the background of new economy. When meeting the competition in the global marketplace, as the stabilizing force of the real economy, manufacturing industry should be developed energetically not only with the support of state policies but also the self-development of enterprises themselves. Cost has a close relationship with the benefit of an enterprise, so, scientific and reasonable control and management of cost may have direct influence on the economic benefit of an enterprise and further improve the core competence of an enterprise.

\section{Importance of the Cost Control of Manufacturing Enterprise}

President Xi has pointed out in the reports of the 19th National Congress of the Communist Party of China that "We have to lay emphasis on the real economy when constructing the modern economy and set the main direction upon the improvement of quality of supply system, which may help dramatically enhance the advantage of economic quality. We have to accelerate the development of a strong manufacturer and the advanced manufacturing industry." "11" Furthermore, premier Li Keqiang also mentioned in the government work report on 5th, March that "We should further lighten the burden on enterprises, especially for the tax rate of industries as manufacturing, communication and transportation, in order to improve the core competence of industries." The manufacturing industry of our country is the strategic industry that will influence the economic lifeline and boasts the important position of the development of national economy. Nowadays, the manufacturing industry of our country has been facing the big problem that we should realize the strategic transformation and adjustment of industrial structure. And in the process of transformation, each national department should lay great emphasis on the improvement and transformation of enterprises. However, enterprises themselves should also slim from the internal since cost has a strongly close relation with the economic benefit of enterprises and directly influences the sale of products and market share. Only with the scientific and reasonable cost control can enterprises nail the support of national policies, improve economic benefit and core competence of enterprises, then further to realize the industrial development and upgrading.

\section{Prominent Problem on Cost Control of Manufacturing Enterprises}

\subsection{Lack of Cost Consciousness of Members of Enterprises}

One third of enterprises of manufacturing industry of our country are large or medium size, as a 
result of which, the traditional cost management of enterprises may only focus on cost accounting. Thus, the idea that cost control is both the base of financial management and the key of lean management of enterprises will always be ignored. Only with better cost control can enterprises realize management efficiency. Cost management will occur in each aspect of manufacturing from research and development of products, material purchase to products production and sale of products, which all embodies the importance of cost management. According to the statistics, most of the manufacturing enterprises have found the significance of cost management, however, which may only be reflected in the process of products production but not in other aspects of manufacturing such as research and development of products and so on. Moreover, enterprises haven't thought deeper about the motivation of cost problems and the effective influence of cost control.

\subsection{Laggard Method of Cost Management}

According to the statistics of the investigated enterprises, 41.6 percent of the enterprises use the target cost management while the other 48.9 percent use the planning cost method. Moreover, 17.6 percent of manufacturing enterprises use the standard costing. Nevertheless, the activity-based costing with advanced management philosophy is barely used. An enterprise is the main entity of cost management and the motivation of management derives from the need of profit maximization of an enterprise. Currently, most of enterprises are using the traditional cost management method while some may even imitate others without integrating their own situation, which may lead to the mismatching of the management method and the organizational structure of enterprises, failure of management and even the unsatisfactory effect of cost management. Some department managers even plaster achievements artificially so as to obtain sound management performance, which makes the cost management a mere formality.

\subsection{Pursuit of One-sided Cost Control}

Nowadays, there exists a misunderstanding of cost control, which believes the meaning of cost control is to decrease the cost of enterprises. However, what cost control can do is achieve the goal of cost management of enterprises with the method of cost management fitting for enterprises themselves in the premise of ensuring the effect of products and accomplishing standards of products. In other words, cost control doesn't mean to decrease the cost and expense of enterprises solely or sometimes even not to spend. According to the investigated enterprises, some enterprises may stop the good implementation plan halfway just for unreasonable reduction of cost, which presents the common phenomenon that enterprises pursue the reduction of cost solely at the price of quality loss of products. All these moves may show the one-sided idea of cost control and put aside the whole interest of enterprises, which may finally cause the neglect of the longtime development goal but merely focus on the immediate interests. The cost control of this type will definitely run in the opposite direction of realization of cost management.

\subsection{Incomplete Cost Control System}

Currently most of manufacturing enterprises treat cost control as the daily routine and request all the members to take part in the management of cost, but all these may just stay in words, which means the control and management of cost are still the job of decision-makers and related departments. And moreover, cost control is all about the post-action control but lacks reasonable and scientific feed forward control of budget of related departments and productive process. 


\subsection{Distortion of Cost Information}

Nowadays, there are many enterprise administrators and financial administrators request finance employee to cook the book, make false report forms and provide unreal information in order to achieve illegal goals, which may cause the cost management information inconsistent with the facts and bring harmful impact on the cost management of enterprises.

\subsection{Set of Organizational Structure Goes against Cost Management}

Most of manufacturing enterprises take the divisional organization as their organizational structure and each department have its own products and markets which are accounted separately. Each divisional department has to set up full functional organization, as a result, there may create more job positions and internal consumption. And each divisional department operates separately, so they may only focus on their own interest but neglect the whole interest of the group. Therefore, the separate and excessive divisions may trigger the waste of resource and go against the management of cost.

In conclusion, manufacturing enterprises should actively enhance the internal cost management and pay more attention to the self-improvement integrating the requirement of cost management while they gradually adapt to the change of the external environment.

\section{Advice on Cost Management of Manufacturing Enterprises}

\subsection{Set up the Idea of Whole Staff Participation of Cost Management}

Under the background of the new era, normal and economic environment, enterprise administrators should establish the idea that the idea and work of cost management is utmost key part, which requires enterprise administrators and decision-makers to have the strategic view and realize the importance of cost management. And what enterprise administrators should do is establish the idea of whole staff participation of cost management, which can also mean that each one should take his responsibility for the management of cost and the work belongs not only to one department but also each single department of the enterprise and each employee. Only with the whole staff participation can one enterprise realize the goal of cost management.

In the work of cost management, enterprises should integrate the advanced philosophy of cost management with their own situation to make plan for the longtime strategic development. They should also timely adjust and correct the strategy of cost management on the base of both the strategic planning of enterprises and the performance of products in the market.

\subsection{Utilization of Advanced Method of Cost Management}

During the process of longtime cost management of enterprises, there occur plenty of management methods such as variable costing, centralized classification and so on. Nowadays, most of manufacturing enterprises of our country are using the traditional cost management method and few enterprises use the activity-based costing, which reveals that the excessively sole method will do harm to the management of cost. Cost management have been wildly used aboard early, so there generate many advanced methods as activity-based costing and so on during the process of management. All these advanced methods should be used for reference to create the new method which fits for enterprises of our country integrated with management organizational structure, corporate culture and feature of production of enterprises themselves. Enterprises can combine the traditional methods with advanced ones for there exists the phenomenon that one enterprise can integrate two or more methods together overseas. 


\subsection{Strengthen the Enterprise Internal Management}

Enterprise cost management is a system engineering which requires scientific and reasonable planning and policies, which can be presented as follow:

Firstly, there should be scientific quota management system. Quota management should adapt to the change of external market environment. Since the market environment are changing constantly and key elements as material also fluctuate dramatically, enterprises have to adjust the quota timely. Otherwise enterprises may face the inaccurate cost accounting, which may finally send wrong messages to enterprises on the decision making of pricing and product structure and have impact on the accomplishment of profit.

Secondly, enterprises should strengthen the asset management system. Most of the administrators of asset management department are trusted by enterprises, however, disordered material measurement will definitely cause the inaccuracy of cost accounting. So, basically, enterprises have to strengthen the asset management system.

\subsection{Complete Cost Management System and Strengthen the Regulatory System}

Effective cost strategical decision derives from cost forecast. And cost forecast is the base of the planning of cost level and detailed goal of cost in certain period and also the method to realize the goal of cost according to compare and analysis. Moreover, enterprises should make plans for cost management based on the detailed content of cost decision and cost control has to base on the cost planning. Finally, daily audit and supervision of cost management should be strengthened in order that enterprises can find and correct the loss and waste during the process of production at any moment.

\section{Conclusion}

In short, with the rapid development of our economy and the need of market mechanism, manufacturing enterprises should do the cost management in many ways, only in this way can the enterprises develop sustainably. If manufacturing enterprises want to realize transformation and upgrading, they cannot rely solely on the support of government policies. Enterprises should scientifically and reasonably control and reduce enterprise costs in order to minimize costs, maximize enterprise value, and better implement the support of national fiscal and taxation policies. To promote the economic benefits of manufacturing enterprises, and then enhance the core competitiveness of independent research and development, accelerate the transformation and upgrading of manufacturing enterprises in China, and achieve industrial upgrading and development.

\section{Acknowledgement}

Research on structural tax reduction for accelerating the Development of equipment Manufacturing Industry in Northwest Shandong Province (subject No.: J18RA074) Scientific Research Project of Shandong University

\section{References}

[1] report of the "Nineteenth National Congress of the Communist Party of China" decisive victory in building a well-off society in an all-round way to win the great victory of socialism with Chinese characteristics in the new era "

[2] Li Mingxiaundefineds analysis of some problems in strengthening the cost control of enterprises [J] Chinaundefineds chief accountant 2016 (07) 